
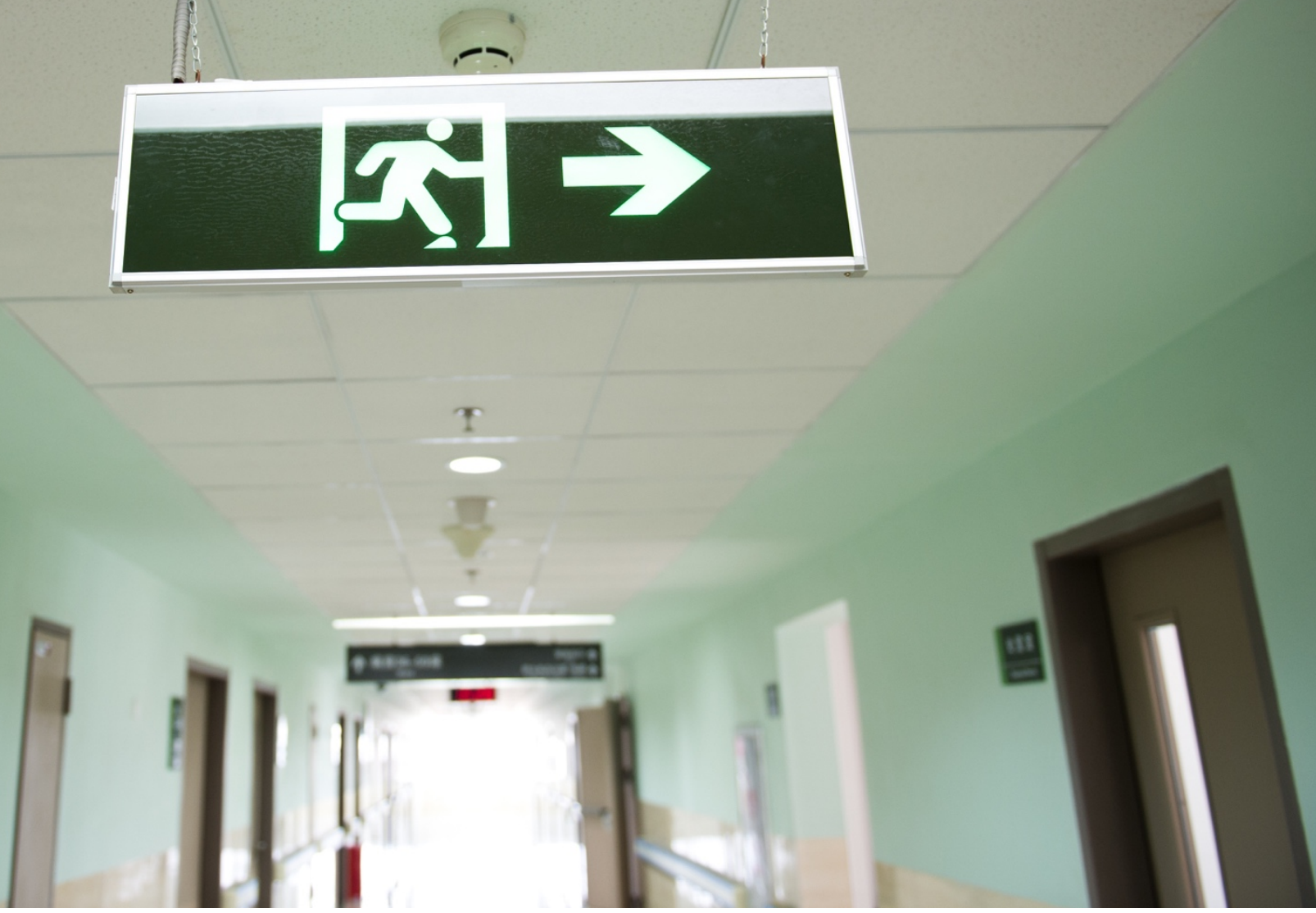

\title{
Commentary
}

\section{Bill 20: Improvement of Access to Healthcare or Mass Exodus?}

Jamie DeMore, MA, $\operatorname{PhD}(\mathrm{c})^{1}$

MJM 2017 16(11)

The current version of Bill 20, formally titled, "An Act to enact the Act to promote access to family medicine and specialized medicine services and to amend various legislative provisions relating to assisted procreation", was passed on November 10, 2015 amidst great controversy. The bill is the latest in a series of ongoing healthcare reforms in Quebec. The Health Minister, Gaétan Barrette, and the Prime Minister of Quebec, Philippe Couillard, insist that Bill 20 has the potential to significantly improve access to healthcare in Quebec (1). The main goal of this bill is for $85 \%$ of Quebecers to have a family doctor by the end of 2017. Should the main goal of the bill be attained, then Bill 20 will be a huge success for the Couillard government.
Many other healthcare professionals especially family physicians; however, do not support the controversial bill because physicians were never consulted during its creation $(1,2)$. Previously made recommendations by family medicine physicians such as providing financial support for the implementation of Electronic Health Records (EMRs), the opening of new family medicine groups across Quebec, and the creation of more provincial super-clinics in order to reach the aggressive goal set by the Couillard administration were not adopted in the final form of the bill $(1,2)$. Others argue that the process of creating new family medicine physician positions in Quebec needs to be completely revamped before the goal of $85 \%$ coverage can be attained. In fact, some physicians and

${ }^{1}$ Department of Family Medicine, McGill University, Montréal, Canada. Corresponding Author: Jamie DeMore, email jamie.demore@mcgill.ca. 
experts fear that the bill will cause many family doctors to move to other provinces to practice medicine, causing the exact opposite effect on access to healthcare as intended(1).

Before the current version of Bill 20 was passed on May 25, 2015, Louis Godin, the president of the Fédération des médecins omnipatriciens du Québec (FMOQ), and Minister Barrette tentatively reached an agreement during a negotiation concerning the controversial bill. In essence, they agreed the implementation of all of the quotas and penalties on family physicians initially proposed in the bill that the family doctors have been so adamantly against would be postponed until the end of 2017. At which point, if $85 \%$ of Quebecers do not have a family doctor, then the quotas and penalties will take effect. If the goal is reached, then Bill 20 will never apply to family physicians (3). Interestingly, Barrette is now stating that Bill 20 was only a way to motivate doctors to rapidly find solutions and he was hoping that he would never have to enforce the quotas or penalties (3). If this is the case, then Barrette's plan worked very well because the FMOQ officially signed the agreement on June 3, 2015 (4). On the other hand, in order to have the support from the health professionals concerning this large change initiative, the solutions of access to healthcare should have come directly from the health professionals and they should have been consulted first before passing Bill 20. Since Barrette's government is using a "top-down" or "iron-fisted" approach instead, resistance against Bill 20 among the health professional has become very high $(2,3)$.

In response to the imminent passing of the bill in May 2015 a group of general practitioners known as Regroupements des médicins Omnipatriciens pour une Médicine Engagé (ROME) held a colloquium in order to enumerate various alternatives to Bill 20 while still providing solutions to increase access to primary care (2). Some of their proposals were included in the agreement between the FMOQ and Minister Barette. First of all, ROME and many other people insist that the specific medical activities (Activités médicales particulières or AMPs) requirement be abolished (2). Currently, family doctors in the first fifteen years of their career are obligated to spend about twelve hours per week, or around $30-40 \%$ of their time, working in emergency rooms, long term residences and other roles to fulfill this AMP requirement. If they do not accomplish this, they are penalized $30 \%$ on their earnings (5). Abolishment of the AMP requirements would allow family physicians to be more present in the community and outside of the hospitals, which has the potential to improve access to primary care (2). Fortunately, the FMOQ and Minister of Health agreement sided with this ROME recommendation and will progressively abolish AMPs (3).

Another possible alternative to Bill 20 brought forth by the ROME summit was to encourage family doctors to utilize the relatively new 'advanced access' or flex time scheduling technique in family medicine practices. This scheduling technique allows family doctors to designate blocks of time each day in their offices for emergency patients to schedule same day appointments (3). This scheduling practice would also help improve their patient fidelity rates and to help ensure that family doctors are not further penalized (4). Currently, family doctors need to reach an $80 \%$ patient fidelity rate or be penalized $30 \%$ of their pay. In other words, family doctors would be encouraged to change their scheduling practices in order to promote patient visits even in urgent situations rather than have patients go to the emergency department. This ROME recommendation was also adopted in the agreement between the Minister of Health and FMOQ.

Some other alternatives to Bill 20 given at the ROME summit were to open more family medicine groups (Groupe de médicine de famille or GMF) in order to encourage more inter-professional collaboration between family doctors, nurses, nurse practitioners, social workers, pharmacists, and to create new super clinics. However, the process to accomplish these two items were not clearly stated in the FMOQ-Barette agreement (4). In fact, super clinics were not even mentioned in the agreement, likely because the Ministry of Health and Social Services (Ministère de la Santé et des Services sociaux or MSSS) is not able to make the financial commitment for their creation. As well, the ROME summit physicians suggested that the MSSS could make GMFs more attractive by paying for administrative support. Moreover, although Electronic Medical Records (EMRs) are listed as a priority in the FMOQ-Barrette agreement, which was another recommendation brought forward from the ROME summit, it is not clearly stated how much financial support the government will provide to fund such implementation projects in family practices. It is admirable to want to improve access to healthcare; however, Bill 20 does not provide clear strategies in order to accomplish this except for abolishing AMPs, encouraging the "advanced access" scheduling technique, and requiring doctors at family medicine residency teaching sites (unites d'enseignement de 
médecine familiale or UMFs) to take more patients. Concrete strategies for goals set forward by the FMOQ-Barette agreement and ROME summit are conspicuously absent from the final bill.

Concerning the latter restructuration of UMFs, this is predictably unpopular at the four medical universities in Quebec. This is mainly because family medicine educators state that teaching residents properly is time consuming and increasing the patient load interferes with academics' schedules, including teaching and research duties. Moreover, the four medical universities state that new patient care quotas will interfere with the number of residents that can be trained per year, which would also have a negative impact on future access to healthcare. Barrette, however, claimed that Quebec has enough family doctors and that the province is not using them to their full potential (1). In essence, this is why he stated that quotas and penalties might be incentive enough for family doctors to take more patients, and thus resolve the access to healthcare issue (6). However, I do not agree with Barrette in the least. When examining the statistics the MSSS bases their numbers on, one can see several issues.

PREMs (or Plans régionaux d'effectifs médicaux) are the new positions that become available every year in Quebec. The two main goals of PREMs are firstly to ensure that all populations from all regions of Quebec are being accurately served and secondly to distribute doctors in all regions in order to offer these services in an equitable manner. Yet, according to Dr. Mark Roper, a family doctor and Director of the Division of Primary Care, Department of Family Medicine at the MUHC, when calculating the number of new PREMs each year the MSSS utilizes the overall number of active physician licenses per area as the denominator. Dr. Roper insists that it would be more accurate to use an overall number of full-time equivalent services consumed in each area as the denominator instead. In fact, Roper stated recently, "despite the availability of this data, the health ministry continues to use the number of doctors working in an area as the indicator of access that determines their distribution of doctors, instead of area residents' actual use of services. This year, six of the twelve Montreal regions will have a net loss of family doctors after predicted retirements are taken into account" (7). Dr. Roper believes the number that the MSSS uses is inflated because many individuals commute into Montreal or other cities for health care. Furthermore, he stated that the inflated number includes retired family doctors, family medicine teachers, family medicine researchers, and hospitalists. Thus, using the full-time equivalent services consumed would create a more accurate picture of the access to healthcare issue (7) and this is my positon as well. Dr. Roper and I agree that by using more accurate data as the denominator or abolishing the use of PREMs altogether would be more beneficial to address the family doctor shortage in Quebec, thus, this would improve access to healthcare.

Due to the passing of Bill 20 in such a top-down fashion, many family doctors are contemplating to leave the province to practice medicine in other provinces $(1,2)$. Many believe that Barrette's 'carrot and stick' approach is too threatening and would rather leave the province than take any more risks. In addition, many medical students see the current political landscape as a reason to consider residency programs outside of Quebec. It is no secret that Quebec physicians are paid lower than Ontario physicians, which is even evident in the difference between what Quebec medical residents make during their residency training and Ontario residents $(1,8)$. Only time will tell if Bill 20 increases the number of Quebec family physicians who choose to move to other provinces and/or decreases the number of family medicine residents who choose their residency programs in Quebec.

Bill 20 has one simple issue: lack of support from the Quebec health professionals. Barrette and the MSSS should have consulted the health professionals in order to ensure that they support these large change initiatives. By enforcing these changes in this manner, Bill 20 will encounter even more resistance than is expected and this is no way to manage change. Moreover, if the MSSS is really aiming for $85 \%$ of the Quebec population to have a family physician by the end of 2017, the Ministry needs to provide financial investment for new super clinics, new GMFs, and new EMR implementation projects. These measures are needed in order to help family doctors do their jobs more efficiently and, thus, this will improve access to healthcare. In addition, as already mentioned, it is crucial that the current usage of inaccurate data to create new PREMs in Quebec changes or perhaps PREMs should be abolished altogether. If these measures are not addressed, access to healthcare may ultimately worsen due to many family physicians moving to other provinces. With the end of 2017 looming, it will be interesting to see if the main goal of Bill 20 is achieved and how Quebec family physicians and Couillard's administration will react to the results. 


\section{References}

1. Fidelman C. Bill 20's Band-Aid Solution: Montreal doctors still weighing their future. Montreal Gazette May 30, 2015

2. Quebec doctors try to sell Gaétan Barrette on Bill 20 alternatives 2015 [Available from:

http://www.cbc.ca/news/canada/montreal/quebec-doctorstry-to-sell-ga\%C3\%A9tan-barrette-on-bill-20-alternatives1.3068500

3. Fidelman C. Barrette backtracks on Bill 20, on condition $85 \%$ of Quebecers have family doctor by 2017 Montreal Gazette May 25, 2015.

4. Entente de principe intervenue entre la FMOQ et la MSSS afin d'accroitre et d'améliorer l'accessibilité aux services médicaux de première ligne 2015 [Available from:

http://www.assnat.qc.ca/fr/travaux-parlementaires/assembleenationale/41-1/journal-debats/20150603so/documents-

deposes.html

5. AMPS [Available from: http://www.fmrq.qc.ca/en/familymedicine/amp.

6. Gaétan Barrette talks FIT tests, elder care and family doctors 2015 [Available from:

http://www.cbc.ca/news/canada/montreal/ga\%C3\%A9tanbarrette-talks-fit-tests-elder-care-and-family-doctors-

1.2793533.

7. Roper M. Opinion: Quebec is managing a first-rate medical system with second-rate data. Montreal Gazette May 15, 2015. 8. Canadian Resident Matching Service (CaRMS) Salaries and Benefits by Province [Available from: https://www.carms.ca/en/match-process/yourapplication/salaries-benefits/. 